\title{
Evaluation of Medicinal Constituent (Gingerol) in Iraq Cultivated Ginger
}

\author{
Dr. Muhannad A.A. AL-Bayaty ${ }^{\mathrm{I}}$, Dr. Falah J. Ibrahim ${ }^{\mathrm{II}} \&$ Dr. Mohammad W. Hayani ${ }^{\mathrm{III}}$
}

\section{Summary}

The evaluation of gingerol as medical entities in Iraq and Jamaica cultivated ginger was done in this experiment. Two different types of cultivated ginger (Iraq and Jamaica) of the same species (Zingiber officinal) were extracted to achieve the subject of this study. Extraction was performed by two different stages: the first stage preparative and extraction. Harvested ginger was prepared for extraction by wash, denotation, drying, grinding, and extracting by acetone under heating. The second stage is separation by two steps via TLC and HPLC. The quality and quantity of oleoresin and gingerol in each step of separation were checked by spots diameter and RF value of spot migration in TLC ginger compounds and quality of whole extract and number of peak in HPLC as well as quantity of gingerol after HPLC separation was done for both Iraqi and Jamaica ginger. The results of comparison between cultivated ginger of Iraq and Jamaica showed significant decrease $(\mathrm{P}<0.05)$ in quantity of extracts and spot diameter of oleoresin where as no significant change $(\mathrm{P}<0.05)$ in gingerol quantities by HPLC separation was found in Iraqi species. These results showed no effect of different cultivation conditions of both peak Jamaica and Iraq species on medical entities of ginger content of gingerol.

\footnotetext{
${ }^{\text {I }}$ Ph.D. Pharmacology and Toxicology Baghdad University / College of Veterinary Medicine

${ }^{\text {II }}$ Ph.D. Biochemistry Baghdad University / College of Veterinary Medicine

${ }^{\mathrm{III}} \mathrm{Ph} . \mathrm{D}$. Horticulture Baghdad University/College of Agriculture
} 


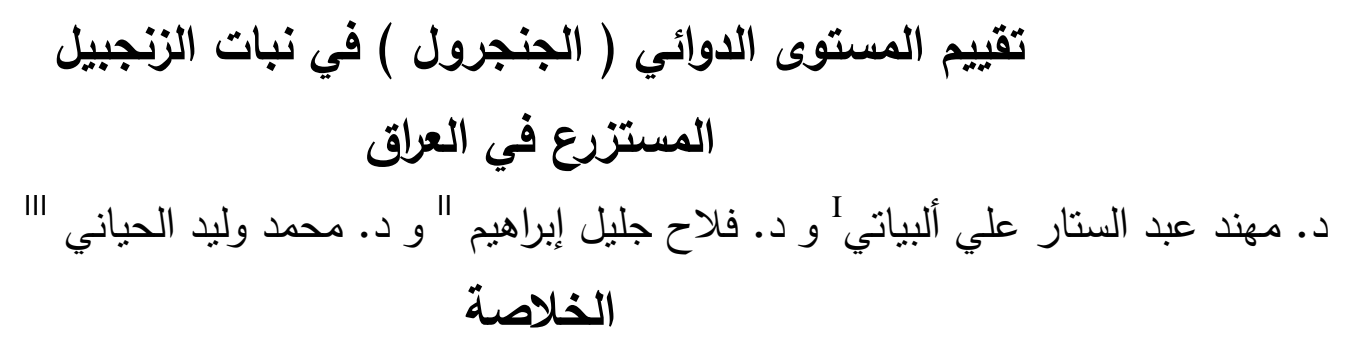

في هذه التجربة درس تقييم المحتوى الطبي للجنجرول Gingerol في الزنجبيل المستزرع في العراق، حيث استخلص نوعان من الزنجبيل ( الأول المستزرع في العراق والثاني المستورد من جاميكا )

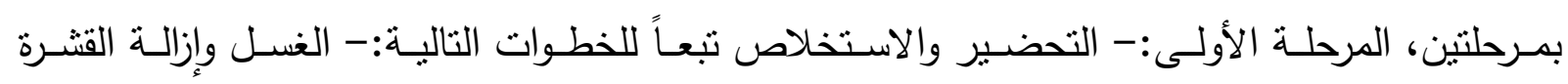
والتجفيف والطحن ثم استخلص بالأستون تحت الحرارة ( استخلاص حار ). المرحلة الثانية:-الفصل

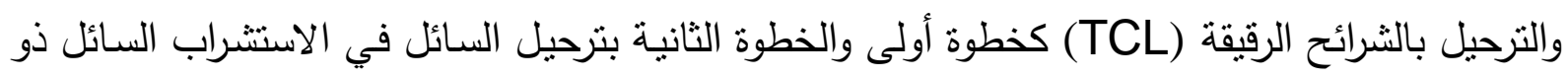

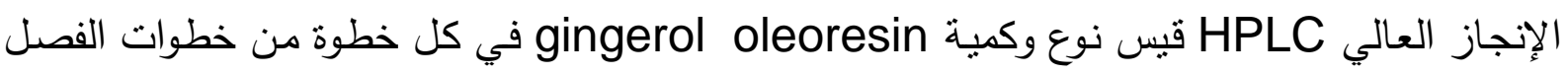

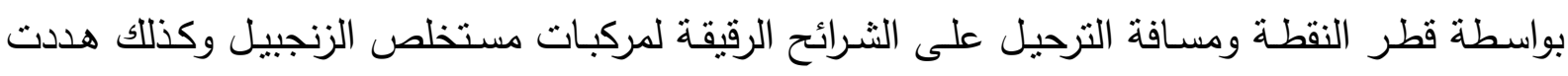

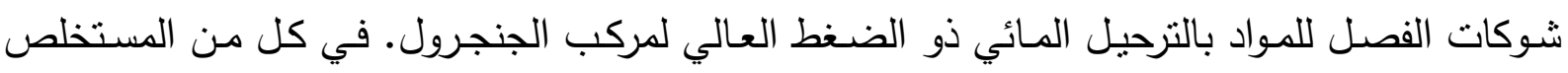

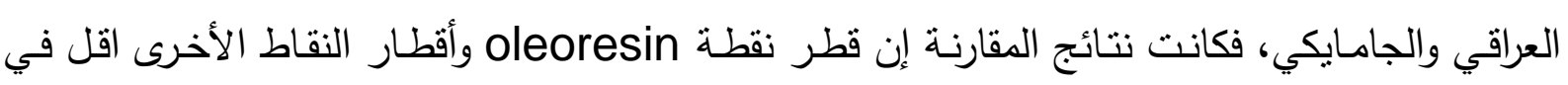

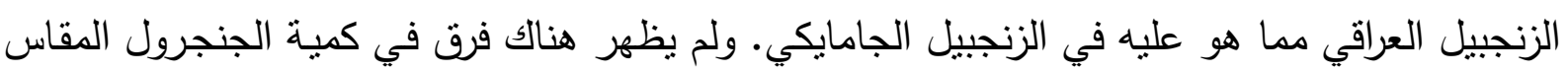
بواسطة HPLC. هذه النتائج أظهرت إن اختلاف ظروف الاستتبات لنبات الزنجبيل في العراق وجاميكا

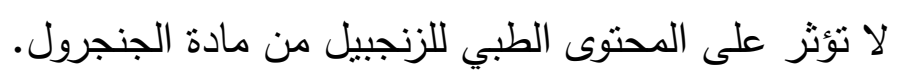

\section{Introduction}

The living plant may be considered a biosynthetic laboratory not for chemical compounds that are utilized as food by human and animals but also for a multitude of compounds that exert a physiologic effect. These chemical compounds give drugs of plant origin their therapeutic properties. Drugs are either used as such in their crude form or they may be extracted, the resulting principles being employed as medical agents, the usual term for these entities is pharmacologically active constituents ${ }_{(1)}$.

The plant kingdom has long supplied us with a large number of excellent drugs, the natural plant drugs have served as useful prototypes for even better medicines $(2)$.

Ginger is one of medicinal plants of some world areas. Ginger rhizome has been used in spices since the ancient civilization. Cocked ginger, fresh

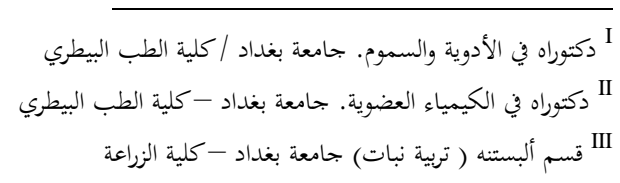


rhizomes or gingerol used for human consumption are rich in starch. The dried rhizome of ginger is a flavor, as condiment, an aromatic stimulant, and a carminative $(3$ and 4$)$.

The ginger plant is a perennial compound herb, Zingiber officinal; Roscoe (Lat.), zingiberaceae (Fam.), ginger synonyms amomum Zingiber is from the Arabic Zindschebil or Zinjabil (5). Asia Standard Herbal Medicine (1993) described the ginger as a perennial herb which has subterranean rhizome and producing stem up to $1.5 \mathrm{~m}$. in height with linear lanceolate sheathing leaves 5$30 \mathrm{~cm}$ long and $8-20 \mathrm{~mm}$. wide, smooth and pale green, the stem bearing few flowers.

Keys (1976) described the rhizome of ginger, rhizoma zingiberis (Rhizoma or root of ginger) is subterranean digitally branched pieces, horizontal, laterally flattened irregularly, i.e. $3-16 \mathrm{~cm}$. long 3-4 cm, wide up to 2 $\mathrm{cm}$ thick, pale yellowish buff or light brown externally, Yellowish brown, internally showing a yellow endodermis separates the narrow cortex from the wide stele.

Awang (1982) recorded the geographical distribution of ginger, which was native to Southeast Asia and probably cultivated in the tropical region both the eastern and western hemispheres. Ginger, however, grows commercially in Africa, China, and Jamaica. Some notion in literature revealed that the ginger rhizome have several pharmacological effects described in pharmacopoae, in traditional systems of medicine and folk medicine but not supported by clinical data $(9,10$ and 11$)$.

Further studies reported experimental and clinical pharmacologic properties seen in ginger extract. Major chemical constituents of rhizoma are essential oil and oleoresin. The composition of the essential oil varies with the geographical origin, but the chief constituent sesquiterpene hydrocarbons seem to remain constant, the main compound includes zingiberene, gingerol and shogals $_{(13) .}$

Recently, in Iraq, ginger was experimentally cultivated during one year with the attempt to grow and distribute the plant. The above-mentioned ginger medicinal compounds or its crude extract may be used in herbal medicine and pharmaceutical preparations.

\section{Materials and Methods}

Extraction of Ginger:

Extraction of both in Iraq cultivated ginger and Jamaica exported ginger was performed in different stages according to (14 and 15).

\section{Preparative and extraction stages:-}


Zingiber officinal was harvested freshly. The ginger rhizome was washed well with continuous tap water several times until wash water is clear. The rhizoma zingiberis was dehuled manually i.e. the outer cortical layers were often completely removed, the dehulled rhizomes were air dried for one week at (35) $\mathrm{C}^{\circ}$ and ground for 5 minutes by electrical grinder ${ }^{\mathrm{I}}$. The flour was stored in kilner kilner jar at $0 \mathrm{C}^{\circ}$ until extraction ${ }_{(16)}$.

The ginger flour was extracted in a 2 liter Erlenmeyer flask containing 1 liter of acetone ${ }^{\mathrm{II}}$. The mixture was stirred for 3 hours under temperature of $40 \mathrm{C}^{\circ}$. The mixture was filtered through (100) $\mu$ mesh sieve, followed by filtration through Wattman $\mathrm{No}_{2}$. Filter paper under vacuum to reduce time of filtration. The filtrate was concentrated to 0.05 liter by rotary evaporation.

\section{Separation stage :-}

TLC method was used for qualitation of ginger extract constituents, which were obtained from previous procedure. The extract constituents were identified by ASEAN method (ASEAN, 1993).

HPLC was employed for qualitation and quantitation of ginger extract constituents according to Yoshikawa method (Yoshikawa et al., 1993), as follows ; HPLC was equipped with injection pumps and U.V. detector, the analytical column was packed with nucleosil C18 and lichroscrb C8, mobile phase; acetone; chloroform ; water $\mathrm{PH}(5.8) \mathrm{V} / \mathrm{V}$ with flow rate $2.6 \mathrm{ml} / \mathrm{min}$.

A retention time of standard zingibrol was determined in analytical set of HPLC and compared with extracted ginger. A calibration graph was obtained by serial dilution of standard and internal standard (phenol), which was corrected by the simultaneous internal standard and external standard, was used to calculate the concentration of gingerol extract in unknown samples.

\section{Results}

The acetone ginger extract was obtained in the form of yellowish brown concentrate (Figure 1). The yield of Iraq and Jamaica ginger extract was $8.41 \mathrm{~g} / \mathrm{kg}$ and $10.69 \mathrm{~g} / \mathrm{kg}$ respectively. Table $(1)$, showed significantly $(\mathrm{P}<0.05)$ lower yield of Iraqi ginger extract than Jamaica ginger extract.

TLC identification method displayed different RF values of ginger extract, the predominant oleoresin appeared as a large spot with (11.3) RF value, identified and colored by fluorescent light $254 \mathrm{~nm}$ and Iodine vapor. The spot diameter of oleoresin of Iraqi ginger extract was significantly lower $(\mathrm{P}<0.05)$ than that of Jamaica ginger extract.

After HPLC separation of ginger extract, the peaks obtained are shown in figure 2. There are six peaks with gingerol and phenol as internal standard in

\footnotetext{
${ }^{\text {I }}$ Elma electrical grinder. London.

${ }^{\text {II }}$ BDH Company LTd
} 
both Iraqi and Jamaica ginger extract. The quantity yield of gingerol was $0.11 \%$ and $0.10 \%$ at retention time of 6 minutes as compared to standard gingerol in both Iraqi and Jamaica ginger extract respectively. No significant differences $(\mathrm{P}<0.05)$ of quantity between the two types were observed.

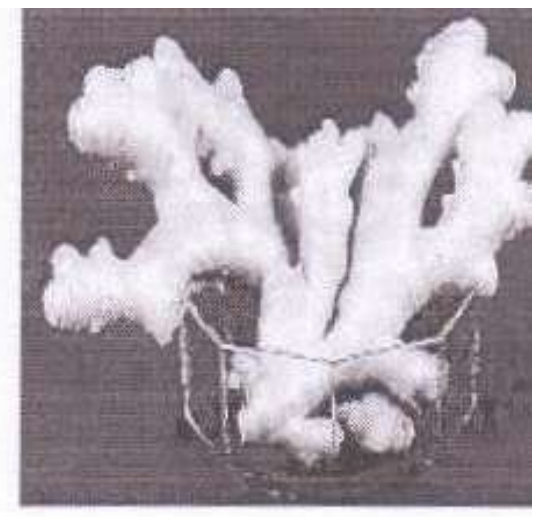

A

B

Figure (1): Photograph of ginger plant rhizoma, yellowish brown, digitally branch

rhizoma

A. Iraqi cultivated ginger.

B. Jamaica cultivated ginger.

\begin{tabular}{|cc|c|c|}
\hline \multirow{2}{*}{$\begin{array}{c}\text { Types of Ginger } \\
\text { Parameters }\end{array}$} & \multicolumn{2}{c|}{ Iraq } & Jamaica \\
\cline { 3 - 4 } & $\%$ & $0.841 \pm 0.065$ & $1.069 \pm 0.036 \mathrm{~A}$ \\
\hline Extract yield & $\mathrm{cm}$ & $1.0 \pm 0.003$ & $1.6 \pm 0.006 \mathrm{~A}$ \\
\hline TLC spot diameter & No. & 6 & 6 \\
\hline HPLC peak & $\%$ & $0.011 \pm 0.00016$ & $0.010 \pm 0.00018$ \\
\hline Gingerol yield & & \multicolumn{2}{c|}{. } \\
\hline
\end{tabular}

Table (1) Evaluation of ginger extract and Gingerol in different setting of analysis.

Values are presented as mean \pm SEM ( $n$ : seven batches)

A: significant $P<0.05$ 


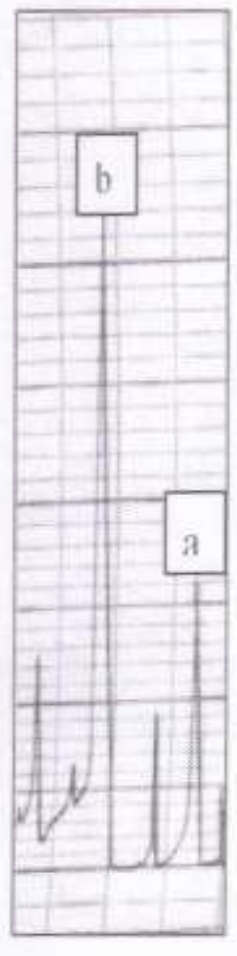

1st

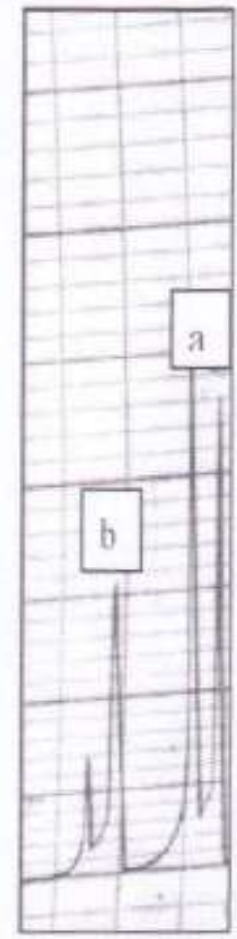

2nd

Figure (2): HPLC separation of gingerol. Peak (a) gingerol in acetone. Peak (b) is phenol, added as internal standard. The column packed with Nucleosil C18 was used and acetone: chloroform;water ( $\mathrm{pH} 5.8$ ) as mobile phase UV detector $455 \mathrm{~nm}$. Flow rate $2.6 \mathrm{ml} / \mathrm{min}$. The retention time was (6) min.

$1^{\text {st }} \quad$ This figure show HPLC of gingerol in Iraq cultivated ginger. The peak (a) represents the location of gingerol (0.3) $\mathrm{mg}$ phenol (0.02) $\mathrm{mg}$, peak (b) and showing many peaks of unknown metabolites and contaminants.

$2^{\text {nd }}$ Illustrated here are HPLC of gingerol in Jamaica cultivated ginger. The peak (a) and peak (b) represent location of gingerol (0.3) $\mathrm{mg}$. phenol (0.02) $\mathrm{mg}$ respectively. Many peaks of unknown metabolites and contaminants were exhibited. 


\section{Discussion}

Evaluation of Iraq cultivated ginger extract and medicinal constituent gingerol was under taken. In this, two stages were performed to compare the Iraqi cultivated ginger with tropical Jamaican ginger as a native growing plant.

Acetone extraction of Iraqi ginger yielded an extract quantity significantly lower than that of Jamaica ginger extract. This result may be attributed partially to lesser oleoresin due to the different cultivation foundations the tropical region in both Iraq and Jamaica $(8,7,13,14,17)$, that came in agreement with spot diameter of ginger extract in TLC separation. The TLC separation results showed smaller oleoresin spot diameter of Iraq ginger as compared with Jamaican ginger (Table 1), this may be attributed to unsuitable environments for ginger growth in Iraq, and presumably to the differences of soil areas (18). Whereas keys (1976) attributed reduction of extracts to reduction of starch bioavailability.

In order to see whether the acetone ginger extract was responsible for the reductive effects, which were seen in Iraqi cultivated ginger, the HPLC separation and purification method was performed. HPLC separation method showed no differences in peak number for medical constituent of Iraqi ginger as composed to Jamaican ginger extract, which can be attributed to Iraq atmospheric condition. Whereas the peak area ratio of Iraq ginger extract peaks were lower than peak area ratio of Jamaican ginger extract peaks; the peak area ratio of gingerol exhibited no differences between Iraq and Jamaica extracts. These gave the indication that the quantity of Iraqi ginger extract in our culture is less than Jamaican ginger extract, since the peak of medicinal gingerol of Iraqi ginger extract is coinciding with gingerol of Jamaica ginger extract peak; these results are in agreement with the result of Yamahara (1991). Suekawa (1984) and WHO (1998) who suggested that this was attributable to conversion of shogals.

Dehydrated form of ginger metabolite having the same benzene ring to gingerol (hydrated form) may be due to survival phenomena of plant leading to liberation of the ATP energy through conversion process of metabolism.

\section{References}

1. African Pharmacopia (1985). Vol.32 1st ed. Logos Organization of Africa Unity, Scientific Technical, Research Commission.

2. Asian Standard Herbal Medicine (1993). Vol. 1 Jakarta .Asia countries, Large Springer.

3. Awang, D.V.C. (1982). Ginger Canadian pharmaceutical Journal, 125: 309-301. 
4. Balandrin , M.F. ; Klocke , J. A. ; Wurtale , E. S. and Boillinger , W. H. (1985). Natural plant chemicals; source of industrial and medical materials .Science. 228: 1154.

5. Bisset, N.G. (1994). Max Wichtl' herbal drug and phyto pharmaceuticals Boca Ratonj, FL.CRC. Press.

6. Chang, H.M. (1986). Pharmacology and application of Chinese material medica, Vol.1. Singapore, World scientific publishing.

7. German commission E. Monograph (1988). Zingiberis Rhizoma, Runde Sonzeiger; 85: 5 may.

8. Ghazanfar,S. A. (1994). Handbook of Arabian medical plants. Boca Raton, F.L. CRC. Press.

9. Guenther,e. (1959). Ginger in Jamaica, Coffee and Tea Ind. 82(1): 169.

10.Keys, J.D. (1976). Chinese Herbs, their Botany, Chemistry and Pharmacodynamic, Rutland, V.T. C.E. Tuttle.

11.Mustafa, T.; Srivastava, K. C. and Jensen, K.B. (1993). Drug development reported pharmacology of ginger (Zingiber officinal) .Journal of drug development 6: 25-39.

12.Pharmacopea of the people's republic of China (1992). Guangzhou, Guangdong science and technology Press.

13.Taylor,N. (1965). Plant Drugs that Changed the World. New York, Mead. Co. P95.

14.Pravatoroff,N. (1967).Ginger, the properties and chemistry of some natural spicy compounds. Mfg.Chemist. 38(3):40.

15.Suekawa, M. (1984).Pharmacological studies on ginger. I. Pharmacobiodynamics. 7: 836-848.

16.Srivastava, K.C. and Mustafa, T. (1992). Ginger (Zingiber officinal) in rheumatism and musculoskeletal disorders. Medical hypothesis 39: 342348.

17.WHO (1998). Quality control method for medical plant materials .Geneva World Health Organization.

18.Yamahara, J. (1985). Cholagogic effect of ginger and its active constituents Journal of ethnopharmcology, 13: 217. 225.

19.Yamahara, J. (1991). Gastrointestinal motility enhancing effect of ginger and its active constituents. Chemical and pharmaceutical bulletin 38: 43043.

20. Yoshikawa, M (1933). Qualitative and quantitative analysis of bioactive principles in Zingerbers rhizoma by means of high performance liquid chromatography. Yakugaku Zxasshi, 113: 307 -315. 